\title{
Gender Competition for Surviving COVID-19
}

\author{
Hamzullah Khan ${ }^{1}$, Shahtaj Khan ${ }^{2}$ \\ ${ }^{1}$ Associate Professor, Nowshera Medical College, Nowshera, Pakistan \\ ${ }^{2}$ Professor \& HOD Hematology Department, Hayatabad medical complex Peshawar, \\ Pakistan
}

Corresponding Author Hamzullah khan

Mobile:

0092-334-4802902

E mail:

hamzakmc@gmail.com

Key words:

Covid-19,

differences, survival, Mortality
Corona Virus disease termed as COVID-19, is an emerging highly contagious respiratory disease that is caused by novel corona virus. Its main clinical symptoms are fever, dry cough, fatigue, myalgia and dyspnea [1].

In Pakistan, the literature so far covering the prevalence and incidence is deficient. By $24^{\text {th }}$ July 2020 , reported data from government sources declares 270,400 confirmed cases with 5763 deaths. 219783 cases are recovered and 1316 cases are under treatment in high dependency units countrywide. Sindh is the province with highest number of corona cases crossing 115883[2]. Gender and age matters when there is talk about the prognosis and outcome of the disease. A study reported that corona virus is striking and felling more Italian males as compared to females in extreme of age because of their weak immunity status. They further elaborated that Italian model of mortality is a trend mirror of what they observed in China with more causality in male gender and at extreme age[3].
Using the Kaplan Meir test we analyzed the 32 deceased data from our hospital named Qazi Hussain Ahmed Medical Complex Nowshera and district line list for a number of variables including the impact of gender and comparing the survival capabilities of both genders simultaneously infected with COVID19.

We observed that male gender that have contracted COVID-19 in their extreme ages offering less resistance to the virus with poor survival rate as compared to the female's gender where the surviving capabilities for unknown reasons are stronger than those in male gender (Figure 1). Many factors can contribute including low viral load because of less exposure as compared to the male gender in our religious society. Similarly, there could be some un-discovered immune predominance in female gender that confers more immunity and neutralizes the virus.
The surviving chances drops to less than $20 \%$ in male patients with age more than 80 years and up to $40-45 \%$ at age $70 y e a r s$ as compared to $60 \%$ surviving in female gender for the same age groups. In male gender the survival drops vertically with age more than 80years while no such graphical changes are seen for female patients.

Studies have been reported the infection more common in male gender as compared to female gender with a higher mortality in the patient with age> 60 years [4]. However, the literature is still in search of gender conflict in acquiring the disease. One of the possible justifications is that male gender in the earner figure in our social set up, this in term increases the chances of male gender more going out for search of food and live hood, which exposes more to male gender to the risk of COVID-19. Jin et al [5] reported that the prevalence of COVID-19 is same in both genders but men with COVID are more at risk of worse outcome and death independent of age.

More studies are needed to explore this gender preference and the female gender being more 
protective in term of case fatality in COVID-19. This communication would further direct the researchers to know more about the disease and the impact of the demographic variable and its molecular basis under gender perspective.

A review from the Europe and China multicentre studies reported that there is need to better understanding the impact of gender in COVID-19 and to tailor the treatment according to the gender perspective and stressed the therapeutic trials must included gender sensitive analysis[6].

An accumulative integrated approach at individual, national and international level would address the problem and can reduce the burden of the disease. There is need for advocacy on social distancing, avoiding gathering especially in "EidUlAzha", using of face masks and avoiding of travel to an epidemic area with reported COVID-19 cases.

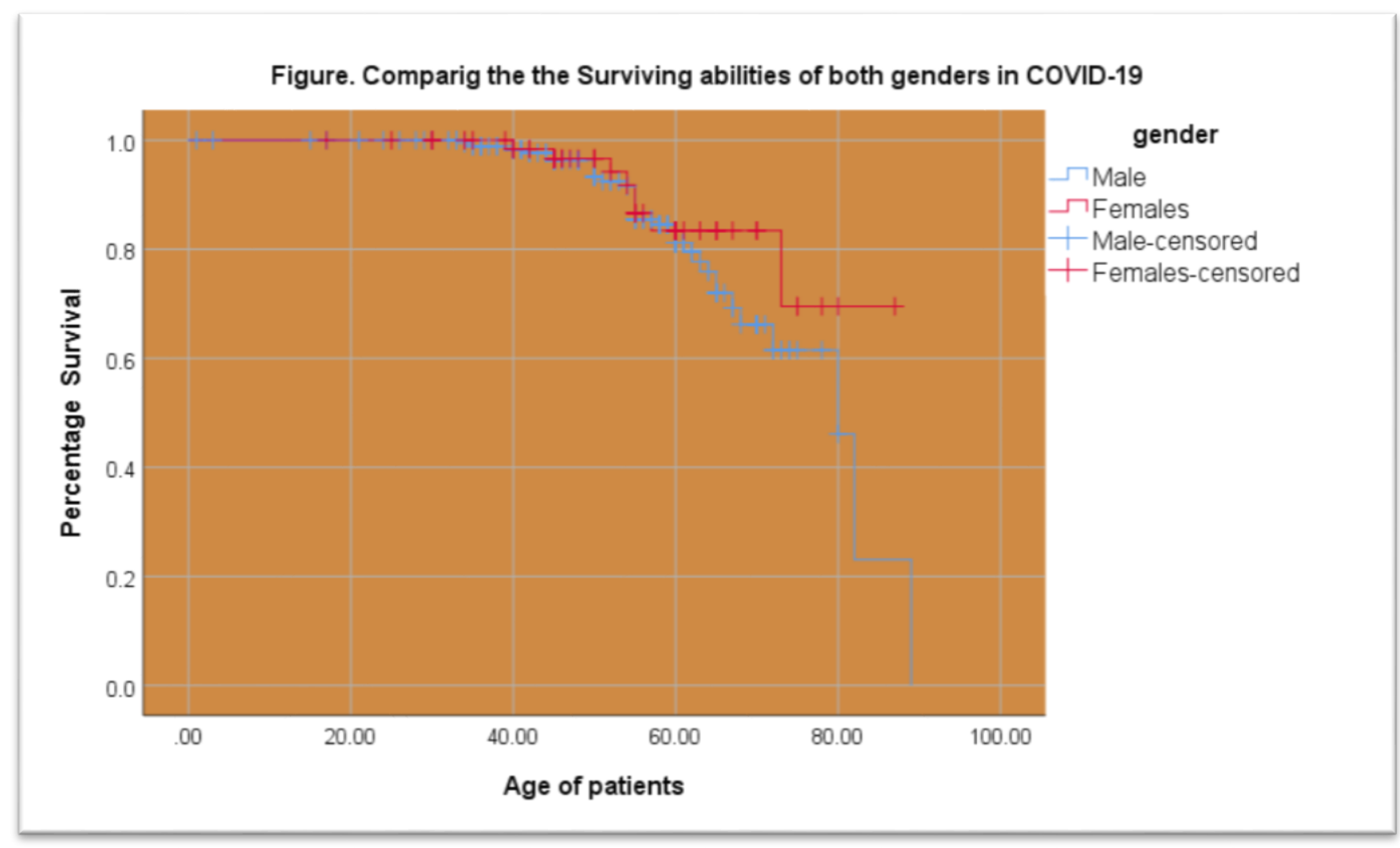

\section{REFERENCES}

1. Chen N, Zhou M, Dong X, Qu J, Gong F, Han Y. et al. Epidemiological and clinical characteristics of 99 cases of 2019 novel coronavirus pneumonia in Wuhan, China: a descriptive study. Lancet. 2020; 395:507-13

2. "Coronavirus in Pakistan - Confirmed Cases". www.covid.gov.pk/. Retrieved 24 July 2020.

3. Cascella M, Rajnik M, Cuomo A, Dulebohn SC, Di Napoli R. Features, Evaluation and Treatment Coronavirus (COVID-19) [Updated 2020 Mar 20]. In: StatPearls [Internet]. Treasure Island (FL): StatPearlsPublishing; 2020 Jan-. Available from: https://www.ncbi.nlm.nih.gov/books/NBK554776/
4. Liu K, Chen Y, Lin R, Han K. Clinical features of COVID-19 in elderly patients: A comparison with young and middle-aged patients. J Infect. 2020; 80(6):e14-e18. doi:10.1016/j.jinf.2020.03.005

5. Jin JM, Bai P, He W, Wu F, Liu XF, Han DM et al. Gender Differences in Patients With COVID-19: Focus on Severity and Mortality. Front Public Health 2020;8:152. Published 2020 Apr 29. doi:10.3389/fpubh.2020.00152

6. Gebhard C, Regitz-Zagrosek V, Neuhauser HK, Morgan R, Klein SL. Impact of sex and gender on COVID-19 outcomes in Europe. Biol Sex Differ 2020; 11(1):29. Published 2020 May 25. doi:10.1186/s13293-020-00304-9. 